\title{
Effect Of Trabeculectomy On Ocular Biometry And Refractive Errors In Pediatric Glaucoma
}

\author{
Nouhoum Guirou \\ Youssouf Dembélé \\ Abdoulaye Napo \\ Théra Japhet \\ Drissa Moriba Coulibaly \\ Amassagou Dougnon \\ Aichata Tall \\ Fatoumata Sylla
}

CHU-IOTA, Université des Sciences des Techniques et des Technologies de Bamako, Mali

Doi:10.19044/esj.2021.v17n29p291

Submitted: 24 May 2021

Accepted: 09 August 2021

Published: 31 August 2021
Copyright 2021 Author(s)

Under Creative Commons BY-NC-ND 4.0 OPEN ACCESS

Cite As:

Guirou N., Dembélé Y., Napo A., Japhet T., Coulibaly D.M., Dougnon A., Tall A. \& Sylla F. (2021). Effect Of Trabeculectomy On Ocular Biometry And Refractive Errors In Pediatric Glaucoma. European Scientific Journal, ESJ, 17(29), 291.

https://doi.org/10.19044/esj.2021.v17n29p291

Abstract

Background: Pediatric glaucoma triggers refractive errors by modifying the biometry of the eye. This study was conducted with the objective of estimating the short-term biometric and refractive changes prior to and post trabeculectomy in pediatric glaucoma.

Material and Methods: A 12-month, descriptive, cross-sectional study was carried out from January to December 2019, using patients operated on for pediatric glaucoma. Pre- and post-operative biometric and refraction measurements were noted. Visual acuity, axial length, corneal diameter and refraction were obtained. All ethical requirements (anonymity, free, informed, and continuous consent) were satisfied. Data analysis was done using SPSS 20.0 .

Results: In the present study, 47 eyes of 27 patients were surgically operated upon, from January 2019 to December 2019 at CHU-IOTA. The predominant sex was male (17 patients) at $63 \%$, giving a sex ratio (M / F) of 
1.7. The mean age was $5.04 \pm 4.24$. Preoperatively, the mean corneal diameter, and D90 were respectively $13.83 \pm 1.51$ and $12.55 \pm 0.99$. Preoperatively, the mean axial length, and D90, were $23.87 \pm 1.29$ and $22.28 \pm 1.07$, respectively. Preoperatively and at three month, the mean myopia $(n=36)$, were respectively $-3.13 \pm 1.83$ and $-1.59 \pm 0.97$. The mean preoperative astigmatism $(\mathrm{n}=47)$ and D90 were respectively, $-1.59 \pm 0.77$ and $-1.23 \pm 0.57$. A statistically significant relationship $(\mathrm{p}<0.05)$ was found to exist between the preoperative and postoperative data of the axial length, corneal diameter, and refractive errors.

Conclusions: Trabeculectomy significantly exerts a short-term positive impact on the biometrics and refraction by modifying the initial measurements and diopters.

Keywords: Trabeculectomy, Biometry, Refractive Errors, Axial Length, Corneal Diameter

\section{Background}

Pediatric glaucoma (from birth to 18 years of age) is potentially blinding, with ocular hypertension present either at the time of birth or as a secondary occurrence caused by iridocorneal angle or anterior segment abnormality (Chraibi, 2017; Detry-Morel, 2001; Papadopoulos,2014; Beck, 2001). Pediatric glaucoma shows annual incidence in the range of 0.3 to 1 per 10,000 births and is manageable mainly by surgical intervention (Papadopoulos,2014; Ho, 2004).

Across the globe, the major causes for visual impairment are refractive errors (ametropia) (Resnikoff, 2008). In fact, pediatric glaucoma triggers refractive errors by modifying the biometry of the eye (Papadopoulos,2014; Boulze-Pankert, 2012; Dehghanian, 2020; Tokoro, 1990; Youn, 1990). From a study performed in Cameroon, pediatric glaucoma appears to bear a relationship to ametropia in 51.9\% of the cases (Moune, 2007).

After Cairns introduced trabeculectomy in 1968 (Cairns, 1968), this procedure has been recognized as the standard first-line of surgical procedure for patients with pediatric glaucoma. Trabeculectomy comprises subconjunctival fistulization of the aqueous humor (Papadopoulos,2014; Cairns, 1968), inducing changes in the biometry producing modifications in the initial refraction (Youn, 1990; Moune, 2007; Cairns, 1968). Several studies indicated the induction of anatomical and / or functional modifications post trabeculectomy (Tokoro, 1990; Zhang, 2009; El-Saied, 2014; Tourame, 2009; Soltani, 2019); however, changes connected to refractive errors, in general, have not been reported often in pediatric glaucoma. 
This study was conducted with the objective of estimating the shortterm biometric and refractive changes prior to and post trabeculectomy in pediatric glaucoma.

\section{Material and Methods}

A 12-month, descriptive, cross-sectional study was performed from January to December 2019, using patients operated on for pediatric glaucoma at CHU-IOTA, in Mali. Patients who underwent trabeculectomy for pediatric glaucoma were included. The exclusion criteria included those patients having a history of trauma, ophthalmic surgery, or other related eye pathologies. Some clinical data like intraocular pressure and fundus were left unrecorded, to keep within the strict framework of this work.

Pre- and post-operative biometric and refraction measurements were noted. The visual acuity was evaluated using the Monoyer scale, while the axial length was acquired employing the QUANTEL MEDICAL biometer. The corneal diameter was assessed with a compass and TOPCON KR-800A keratometer. Refraction was obtained by an optometrist using the HEINE BETA 200 autorefractometer and skiascope.

For all the patients in the study, trabeculectomy was performed under general anesthesia. Post the limbal conjunctival dissection, a $4 \mathrm{~mm} \times 3 \mathrm{~mm}$ scleral flap was done, following which paracentesis was performed. Next, resection was done of a 1.5 x $2 \mathrm{~mm}$ deep scleral flap, followed by iridectomy. The scleral flap was closed with 10/0 monofilament, ensuring that two adjustable sutures were present. At the end of surgery, the anterior chamber was re-formed. All the patients were monitored postoperatively for three months. At one month and three months postoperatively, the data were analyzed.

The parents and children (based on age) were provided with all the information concerning this study and all ethical requirements (anonymity, free, informed, and continuous consent) were satisfied. A descriptive data analysis was done by using SPSS 20.0. All P-values $<0.05$ were considered statistically significant.

\section{Results}

In the present study, 47 eyes of 27 patients were surgically operated upon, from January 2019 to December 2019 at CHU-IOTA. The predominant sex was male (17 patients) at $63 \%$, giving a sex ratio (M / F) of 1.7. The mean age was $5.04 \pm 4.24$, with most cases being found in 0 to 1-year age group, i.e., in $40.74 \%$ of the cases (table I). 
Table I. Age of patients

\begin{tabular}{|c|c|}
\hline Age group & $\mathbf{n ( \% )}$ \\
\hline $0-1$ & $11(40,74)$ \\
\hline $2-5$ & $4(14,81)$ \\
\hline $6-9$ & $5(18,52)$ \\
\hline$\geq 10$ & $72(5,93)$ \\
\hline Total & $\mathbf{2 7}(\mathbf{1 0 0})$ \\
\hline
\end{tabular}

Visual acuity > logMar 0.5 preoperatively, D30 and D90 were 33.33\%, $66.67 \%$ and $87.5 \%$ respectively, as shown in Figure 1.

Figure 1. Evolution of visual acuity preoperatively, D30 and D90

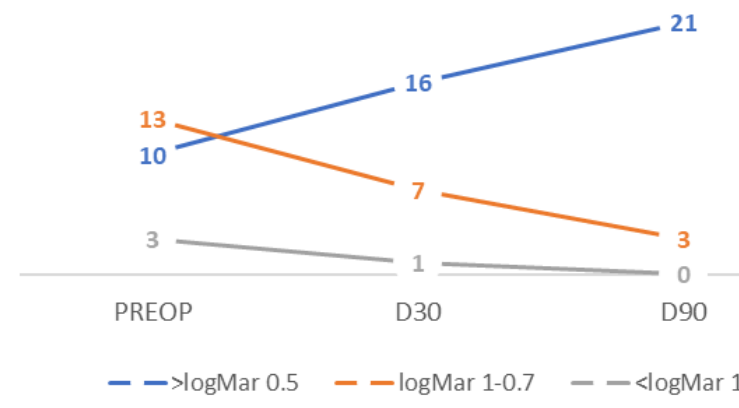

Preoperatively, the mean corneal diameter, D30 and D90 were respectively $13.83 \pm 1.51 ; 12.79 \pm 1.08$ and $12.55 \pm 0.99$. Preoperatively, D30 and D90, the mean axial length, were $23.87 \pm 1.29,22.79 \pm 1.11$ and $22.28 \pm$ 1.07 , respectively. Preoperatively, the mean myopia $(\mathrm{n}=36)$, D30 and D90 were respectively $-3.13 \pm 1.83 ;-2.23 \pm 1.22$ and $-1.59 \pm 0.97$. The mean preoperative hyperopia $(\mathrm{n}=11)$, D30 and D90, were $+1.57 \pm 0.61,+1.96 \pm$ 0.43 and $+1.92 \pm 0.52$, respectively. The mean preoperative astigmatism $(\mathrm{n}=$ 47), D30 and D90 were respectively, $-1.59 \pm 0.77$; $-1.83 \pm 0.62$ and $-1.23 \pm$ 0.57 .

A statistically significant relationship $(p<0.05)$ was found to exist between the preoperative and postoperative data of the axial length, corneal diameter, and refractive errors. Trabeculectomy caused significant modifications by decreasing the dioptric power of the refractive errors, size of the corneal diameter and axial length, as shown in Table II.

Table II. Biometric and refractive mean value preoperatively, D30 and D90

\begin{tabular}{|l|l|l|l|l|l|}
\hline & Axial length & $\begin{array}{l}\text { corneal } \\
\text { diameter }\end{array}$ & Myopia & hyperopia & Astigmatism \\
\hline Preop* & $23,87 \pm 1,29$ & $13,83 \pm 1,51$ & $-3,13 \pm 1,83$ & $+1,57 \pm 0,61$ & $-1,59 \pm 0,77$ \\
\hline D30 & $22,79 \pm 1,11$ & $12,79 \pm 1,08$ & $-2,23 \pm 1,22$ & $+1,96 \pm 0,43$ & $-1,83 \pm 0,62$ \\
\hline D90 (M3) & $22,28 \pm 1,07$ & $12,55 \pm 0,99$ & $-1,59 \pm 0,97$. & $+1,92 \pm 0,52$ & $-1,23 \pm 0,57$ \\
\hline p value & 0,000 & 0,000 & 0,000 & 0,004 & 0,002 \\
\hline
\end{tabular}

*Preop: preoperatively; D30: day 30; D90: day 90 


\section{Discussion}

Glaucoma accounts for 5-10\% of the causes of childhood blindness (Zhang, 2009; Gilbert, 2003; Haddad, 2007). In Mali, it is responsible for $11.3 \%$ of the causes of blindness in children in a school for the blind (Guirou, 2018). Our study was concerned with the biometric and refractive aspects of trabeculectomy in children. The mean age was $5.04 \pm 4.24$ years in our series. The mean age for our cases was higher than most studies that included only congenital glaucoma (Zhang, 2009; Soltani, 2019; Detry-Morel, 2001).

In our study, most of the patients were male (62.96\% of the cases). This is consistent with most studies carried out in different countries (Soltani, 2019; Qiao, 2009; Tchabi, 2007; Makita, 2017; Hoguet, 2016). This male predominance reported by several authors can be explained by the genetics of the disease (Vithana, 2009).

Preoperatively, and three months later, the mean corneal diameter was $13.83 \pm 1.51$ and $12.55 \pm 0.99$, respectively. Preoperatively, in Zhang's series, the mean corneal diameter was $13.10 \pm 0.99 \mathrm{~mm}$ and $11.84 \pm 0.87 \mathrm{~mm}$ five years after surgery (Zhang, 2009). Preoperatively, and three months later, the mean axial length was $23.87 \pm 1.29$ and $22.28 \pm 1.07$, respectively. Several authors reported a noteworthy decrease in the axial length and corneal diameter post trabeculectomy (Boulze-Pankert, 2012; Zhang, 2009).

Post trabeculectomy, the refractive errors also showed significant modification. However, the average astigmatism had escalated to D30, after which it declined to less than the preoperative threshold. Alterations in the refraction have been demonstrated in studies in Iran (Dehghanian, 2020), in France (Boulze-Pankert, 2012), in China (Zhang, 2009) and Egypt (El-Saied, 2014).

\section{Conclusions}

In pediatric glaucoma, several important anatomical changes are evident underlying the functional improvement. Trabeculectomy significantly exerts a short-term positive impact on the biometrics and refraction by modifying the initial measurements and diopters. Further studies are required to estimate the long-term effects.

\section{References:}

1. Chraibi F, Andaloussi IB, Abdellaoui M, Tahri H. Le glaucome congénital. J Société Marocaine D’Ophtalmologie. 2017;(26).

2. Detry-Morel M. Le glaucome congénital. Bull-Soc BELGE Ophtalmol. 2001;49-60.

3. Papadopoulos M, Edmunds B, Fenerty C, Khaw PT. Childhood glaucoma surgery in the 21st Century. Eye. 2014 Aug;28(8):931-43. 
4. Beck AD. Diagnosis and management of pediatric glaucoma. Ophthalmol Clin N Am. 2001;14(3):501-12.

5. Ho CL, Walton DS. Primary congenital glaucoma: 2004 update. J Pediatr Ophthalmol Strabismus. 2004 Oct;41(5):271-88; quiz 300-1.

6. Resnikoff S. Global magnitude of visual impairment caused by uncorrected refractive errors in 2004. Bull World Health Organ. 2008 Jan 1;86(1):63-70.

7. Boulze-Pankert M, Zanin É, Matonti F, Benso C, Toesca É, Denis D. Rééducation de la part fonctionnelle de l'amblyopie dans le glaucome primitif infantile opéré, recul de 11ans. J Fr Ophtalmol. 2012 Mar ;35(3):181-6.

8. Dehghanian Nasrabadi F, Hashemi H, Aghazadeh Amiri M, Fakhraie G, Akbarzadeh Baghban A, Jafarzadehpur E, et al. Evaluation of Changes in Refractive Errors Before and After Trabeculectomy and Shunt Surgery. Clin Optom. 2020 Jul;Volume 12:107-12.

9. Tokoro T, Funata M, Akazawa Y. Influence of intraocular pressure on axial elongation. J Ocul Pharmacol Ther. 1990;6(4):285-91.

10. Youn DH, Yu YS, Park IW. Intraocular pressure and axial length in children. Korean J Ophthalmol KJO. 1990;4(1):26-9.

11. Moune E, Bella-Hiag A. Le glaucome juvénile au Cameroun. Bull Soc Belge Ophtalmol. 2007; 305:69-77.

12. Cairns JE. Trabeculectomy: preliminary report of a new method. Am J Ophthalmol. 1968;66(4):673-9.

13. Zhang X, Du S, Fan Q, Peng S, Yu M, Ge J. Long-term surgical outcomes of primary congenital glaucoma in China. Clinics. 2009;64(6):543-51.

14. El-Saied HM, Foad PH, Eldaly MA, Abdelhakim MA. Surgically induced astigmatism following glaucoma surgery in Egyptian patients. J Glaucoma. 2014 ;23(3):190-3.

15. Tourame B, Younes NB, Guigou S, Denis D. Glaucome congénital : devenir visuel et pressionnel. Résultats d'une étude sur 11 ans. J Fr Ophtalmol. 2009 ;32(5) :335-40.

16. Soltani L, Ahammou H, Baroudi S, Essafi H, Hajji I, Moutaouakil A. Glaucome congénital : pronostic pressionnel et visuel après trabéculectomie et rééducation de la part fonctionnelle de l'amblyopie. J Fr Ophtalmol. 2019;42(1):57-62.

17. Gilbert C, Rahi J, Quinn G. Visual impairment and blindness in children. In: Johnson GJ, Minassian DC, Weale RA, et al, eds. The Epidemiology of Eye Disease, 2nd ed. London: Arnold; 2003;26086.2003. 
18. Haddad MAO, Sei M, Sampaio MW, Kara-José N. Causes of visual impairment in children: a study of 3,210 cases. J Pediatr Ophthalmol Strabismus. 2007;44(4):232-40.

19. Guirou N, Thera JP, Abba KY, Dougnon A, Traoré L, Bamani S, et al. Causes of blindness in children attending a school for the blind in Mali. Médecine Santé Trop. 2018 Oct;28(4):439-42.

20. Qiao C, Wang L, Xin T, Tao W, Yang D, Wang N. Epidemiology of hospitalized pediatric glaucoma patients in Beijing Tongren Hospital. Chin Med J (Engl). 2009 ;122(10):1162-6.

21. Tchabi S, Sounouvou I, Yehouessi L, Doutetien C, Bassabi SK. Le glaucome congénital au CNHU de Cotonou : A propos de 27 cas. Mali Méd. 2007 ;22(4):14-7.

22. Makita C, Ngabou CN, Madzou M. Glaucome juvénile primitif : Aspects épidémiologiques et cliniques. Ann Sci Santé. 2017 ;16(2).

23. Hoguet A, Grajewski A, Hodapp E, Chang TP. A retrospective survey of childhood glaucoma prevalence according to Childhood Glaucoma Research Network classification. Indian $\mathrm{J}$ Ophthalmol. 2016;64(2):118.

24. Vithana EN, Aung T. Exploring the Basis of Sex Bias in Primary Congenital Glaucoma. J Ophthalmic Vis Res. 2009 4(2):3. 